\title{
Consideration Upon Improving the Online Teaching Platform Development of Ideological and Political Theory Courses
}

\author{
Zhang Shudong \\ College of Marxism Changchun University of Science \\ and Technology \\ Changchun China \\ zhangshudong@cust.edu.cn
}

\author{
Chen Chunyan \\ College of Marxism Changchun University of Science \\ and Technology \\ Changchun China \\ chenchunyan@cust.edu.cn
}

\begin{abstract}
Based on the necessity of building the online teaching platform of ideological and political theory courses, the essay discusses the design of the basic module of the online teaching platform of ideological and political theory courses, in order to enhance the effectiveness of ideological and political theory courses.
\end{abstract}

Keywords-Ideological and political theory courses; Online Teaching Platform

It is a strategic task of fostering builders and successors of socialism with Chinese characteristics and accelerating the great goal of promoting socialist modernization to strengthen and improve the ideological and political teaching of university students. The ideological and political theory teaching is the main way and main field of ideological and political teaching of university students. Strengthening the information construction of ideological and political theory courses, constructing the online platform, and launching the online teaching are the necessary requirement of innovating the ideological and political teaching of university students, which is of great practical significance.

\section{THE NECESSITY OF CONSTRUCTING THE ONLINE PLATFORM OF THE IDEOLOGICAL AND POLITICAL THEORY} COURSES

A. Constructing the online platform of the ideological and political theory courses is the requirement to adjust to the development of the Internet age

The 21 century is the time that the human entering the information networking age comprehensively. Internet is changing people's work, study and lifestyle, and emerging in the campus life thoroughly, meanwhile it is changing the ideas, values, behavior patterns and mental health of the university students. The university students are the main participants of the Internet society, which need us to improve the construction of the ideological and political theory online teaching platform, in order to make the students focus on the online courses, provide a platform to study the political knowledge and communicate with each other, and the workers focused on the ideological and political teaching would make clear the ideas of the students and come up with effective methods.
B. Constructing the online platform of the ideological and political theory courses is the requirement of enhancing the effectiveness of the ideological and political theory teaching

First, on the online platform, the interactive teaching pattern of the ideological and political theory courses sets the Internet which is broad and regardless of time limits as the platform, which could enrich the teaching contents and improving the direction of the teaching contents design. Second, on the online platform, the interactive teaching pattern of the ideological and political theory courses sets decentrative and interactive Internet as the platform, is beneficial to make up the equal, open, democratic, free and sincere interactive behaviors, publicize the entity of the university students, stimulate the problem awareness, thinking awareness and communication awareness of the university students, meanwhile the teachers could understand the real thinking of the university students and touch the inner world of the university students, so as to improve the communication among the ideas of the interactive entities. This positive entity relation maintains inertia, which could expand in the classroom teaching, in order to enhance the interaction and effectiveness of the classroom teaching and make up the deficiency of the classroom teaching.

C. Constructing the online platform of the ideological and political theory courses is the requirement of improving the self-study ability of the students

The university students is becoming mature with various demands after entering the universities, which is different with the middle school period. In the middle school period, the classroom teaching could meet the requirement of the students. Under the great pressure to be enrolled with university, the students only want to learn the knowledge, regardless of real application. They want to enter into the ideal universities by only learning knowledge. In the university, the students need to improve their abilities besides knowledge. Teaching him to fish is much more useful than giving them fish, which means developing the self-study ability of the students is more useful than teaching the knowledge simply. The online teaching node designed by the online platform of the ideological and political theory courses needs the students to study and solve related problems by themselves, make the students study voluntarily, develop the abilities of use the theories flexibly and deal with 
the problems, in accordance with the requirement of the individual development and comprehensive development of the students in the university period. As result, it could be accepted by the students.

\section{THE MODULE DESIGN OF IDEOLOGICAL AND} POLITICAL THEORY NETWORK TEACHING PLATFORM

As the expansion of theory causes, the network teaching platform of ideological and political theory causes should embody the characteristic of systematic study of knowledge, as well as the assessment of the knowledge. The users could communicate with each other on the platform at any time. Therefore the module design consists of three components.

\section{A. Knowledge navigation module: Expansion of the classroom teaching}

The module is designed according to the characteristic of the ideological and political theory causes and the situation of the learners, which should combine the composition of the static content and dynamic teaching activity, in order to make the platform convey plentiful information, maintain abundant resource, cover large field and contain flexible teaching methods. Therefore, the platform should not only contain the contents from the classroom teaching and books, however, it should expand beyond the classroom teaching. The module consists of two kinds of teaching resources: One kind is basic teaching resources, including teaching outline, teaching plan, CAI, references and item pool. As result, the students could learn related contents on the Internet at any time, review the knowledge taught by the teachers that they want to make clear, and preview the contents the that teachers need them study ahead of time. The teachers could organize the students to discuss over the problems using the spared time, or focus on the specific problem comprehensively. In this way, it could avoid that the teachers have to mention every points while could not make the students understand every points completely. It could also avoid that the students could not grasp the key points because of the vague levels. The other kind is additional teaching resources including classic guidance, current affairs aspect and the latest achievement of theory. The classic guidance mainly provide symbolic classic works of Marxism theory, with related questions. It will help the university students possess the theory and thinking way of Marxism; The current affairs aspect is committed to put the Marxism theory into practice through the social development reality analyzed by the famous scholars; The latest achievement of theory aims at assisting the university students find out the latest achievement of Marxism, so as to get rid of the false trend of thoughts that the Marxism is out of fashion or invalid.

The module design should notice the interaction of the teaching process, the openness of the teaching contents and flexibility of the teaching methods. The comment area, where other teachers and students could express their ideas should be located behind the related contents in this module. The design of the module will be improved successively according to the opinions from the teachers and students. Although the module combines with the classroom teaching content, it change the movement patterns of the teaching information. The teaching contents are more open to the public and the teaching cases and materials could be added or deleted or changed at any time. It could reflect the teaching contents of the ideological and political theory causes are timely and comply with the age.

\section{B. Capacity display module: Enhancing the humanistic quality of students}

The key function of the module design is to lead the students enrich their humanities and social science knowledge, providing foundation of humanistic quality for the ideological and political theory causes study, and improving the capacity of putting the theory into practice. The module consists of three teaching resources: Competition resources mainly consists of selection scope, idea forum and academic lecture. Regarding the competition teaching, the traditional mode that participants compete, the specialists select the winners and the students watch the competition should be shifted to make live videos for every competitors respectively, encouraging all students to score for the competitors. In this way, the students are more likely to participate the teaching activity more willingly and actively. At the same time, it could break out the limitation of time and space, launch ideological and political teaching with unprecedented scale, and enlarge the coverage of the teaching. Activity teaching resources consist of entering society, history review, project management and achievement display. The university and the students could save a large amount of expense for the practice base through the online virtual "practice base", avoid wasting time on the way and vigor while they could also know the real experience by themselves. Although "practice base" is virtual, the "experience" is real rather than virtual. Therefore it would also achieve the teaching goal of site visit. Interest teaching resources mainly consist of video resources and task resource library. The students could be encouraged to learn the causes through the introduction of the academic thoughts and biography of the Marxism theorists and reading the videos related to the cause.

\section{Interactive module: Virtual realization of the interactive teaching}

The key point of the module design is to build a platform for the online communication, equal dialogue, and psychological counsel, in order to make the practice teaching web to become students' favorite website which is combined of idea, theory, knowledge, interest and practical use. The study forum, online test and Q\&A tutor should be involved of the interactive module, so that the teachers could follow the achievement of the learners effectively, for example, the teachers could follow the study process of the students, launch online discussion and cooperative study, check the students' online homework, answer the students' problems or provide psychological counsel, and provide instruction for the learners.

The online tests and O\&A tutor are relatively simple. In order to make the cause systematic and theoretical, the study forum of the module shouldn't miss teachers' initiative 
instruction. This forum should provide a specific display and discussion area. The so-called display means that the teachers and the students could display their understanding of the ideological and political theory study, their views about the social focus by publicizing online essay, and set up relatied agenda by themselves. The so-called discussion means the teachers and students express their opinions upon the points of view in the essay. The style of the comment could refer to the "No comment, no news" style on the news website. Comment area is located behind every essay. This way is quite simple, practical and concentrated of topics. The displayed online essays published by the teachers should be of great value, which means the essays should be of theoretical depth and rather insightful, which could inspire the students. The content should be related to the teaching content and the students must feel interested in the topics. The good essays found on other websites could be reproduced as well, in order to enrich the resources of the essays. The ideological and political theory teaching will leave students some essay homework, requiring students to work out essays related to the sensitive topics in their own life and the society. There are some good essays among these essays. The teachers could recommend the students to publish their essays here, to make the students interested in the study. There would be more students make comment behind the essays, and there would be more teachers and students involved in the activity to make the teachers and students communicate more on the platform.

\section{Conclusion}

The ideological and political theory courses network teaching platform can enrich the teaching style, expand the amount of teaching information and enhance the attractiveness of the ideological and political theory courses.
At the same time it can stimulate the students' interest and eagerness to learn. Though this network platform gradually the students have formed such good habits of questioning, exploring and positive attitude toward study. It can also stimulate the enthusiasm of students to participate in the process of learning.

While in the mean time, we should realize clearly that is only an effective supplement to traditional classroom teaching and could not be completely replaced by traditional teaching mode. We can achieve the utmost effect of teaching through the effective combination of online teaching and traditional teaching.

\section{REFERENCES}

[1] Du Chunmei The Analysis of Interactive Teaching Mode of Ideological and Political Courses on the Online Platform, CCP Building and Ideological Teaching, 2010.

[2] Yang Liyan, Chen Wenbin, The Consideration of Improving The Online Teaching Platform of Ideological and Political Theory Causes, Aug. 2010 Ideological and Political Teaching Study.

[3] Zhang Wenming, Discussion on the Ideological and Political Teaching of University on New Media Tech Platform 2 Journal of Tongren University.

[4] Wang Xiuge, Wang wei, Constructing New Complementary Mode of Practice Teaching with Theoretical Teaching in Ideological and Political Theory Course, Periodical Guide for Ideological and Political Theory Course, August 2012.

[5] Dong Jinquan, Ganqin, The Application Mode of VR Technology in University Practical Ideological and Political Theory Course, Journal of Tonghua Normal University, May 2011.

[6] Yang Liyan, Chen Wenbin, Reflections on the ideological and political theory courses network teaching platform construction, Ideological and Political Education Research, Aug 2012. 